\title{
Sequential Steps of Chromosomal Differentiation in Atlantic Surgeonfishes: Evolutionary Inferences
}

\author{
Paulo Roberto Antunes de Mello Affonso, ${ }^{1}$ Maria Aparecida Fernandes, ${ }^{2}$ \\ Josivanda Santos Almeida, ${ }^{1}$ and Wagner Franco Molina ${ }^{2}$ \\ ${ }^{1}$ Departamento de Ciências Biológicas, Universidade Estadual do Sudoeste da Bahia, 45206-150 Jequié, BA, Brazil \\ ${ }^{2}$ Departamento de Biologica Celular e Genética, Universidade Federal do Rio Grande do Norte, 59078-970 Natal, RN, Brazil
}

Correspondence should be addressed to Paulo Roberto Antunes de Mello Affonso; paulomelloaffonso@yahoo.com.br

Received 4 May 2014; Accepted 25 July 2014; Published 12 August 2014

Academic Editor: Joao P. Barreiros

Copyright (C) 2014 Paulo Roberto Antunes de Mello Affonso et al. This is an open access article distributed under the Creative Commons Attribution License, which permits unrestricted use, distribution, and reproduction in any medium, provided the original work is properly cited.

\begin{abstract}
Surgeonfishes are a species-rich group and a major biomass on coral reefs. Three species are commonly found throughout South Atlantic, Acanthurus bahianus, A. chirurgus, and A. coeruleus. In this paper, we present the first cytogenetic data of these species, revealing a sequential chromosomal diversification. A. coeruleus was characterized by a relatively conserved karyotype evolved by pericentric inversions of some pairs $(2 n=48,2 s m+4 s t+42 \mathrm{a})$. In contrast, the karyotypes of A. bahianus $(2 n=36)$ and A. chirurgus $(2 n=34)$ were highly differentiated by the presence of six large metacentric pairs in A. bahianus $(12 \mathrm{~m}+2 \mathrm{sm}+4 \mathrm{st}+$ $18 \mathrm{a})$ and $A$. chirurgus $(12 \mathrm{~m}+2 \mathrm{sm}+4 \mathrm{st}+16 \mathrm{a})$ probably derived by chromosomal fusions that corroborate their closer relationship. A discernible in tandem fusion represents an autapomorphic character to A. chirurgus. In spite of macrostructure variation, single nucleolar organizer regions (NORs) on short arms of a subtelocentric pair and similar distribution of C-bands were observed in the three species. Overlapping of chromosomal data with molecular phylogeny indicated pericentric inversions which took place nearly at $19 \mathrm{Ma}$ while centric fusions are as recent as $5 \mathrm{Ma}$. A physical mapping of coding and noncoding sequences in Acanthurus could clarify the role of additional rearrangements during their chromosomal evolution.
\end{abstract}

\section{Introduction}

Acanthuridae are a monophyletic fish family composed of about 80 species, popularly known as surgeonfishes or tangs [1]. This is an ancient group (nearly $54 \mathrm{Ma}$ ) and most of genera (Acanthurus, Naso, Paracanthurus, Zebrasoma, and Ctenochaetus) diverged between 17 and $21 \mathrm{Ma}$ in Early Miocene [2].

Apparently, the Pacific Ocean is the center of origin of surgeonfishes, retaining most of Acanthuridae richness [3,4]. Further colonization events resulted in distribution of this family to virtually all tropical and subtropical seas of the world, but Mediterranean Sea $[1,3]$. The genus Acanthurus is the largest within the family, but monophyly of the genus is still controversial [2-5]. This fish group is morphologically and ecologically diversified, mainly in relation to foraging behavior and dentition, composing one of the most representative herbivorous fish group on coral reefs $[2,6]$.
A total of four species of Acanthuridae, all belonging to the genus Acanthurus, are present in western Atlantic [7]. Three species are common along the Brazilian coast (Western South Atlantic): Acanthurus coeruleus (blue tang), A. bahianus (barber surgeonfish), and A. chirurgus (doctorfish) [7, 8]. Another Acanthurus species (A. monroviae) was also recorded off southeastern coast of Brazil, but it seems to be an occasional occurrence [9]. Moreover, A. bahianus was thought to range from USA to southern Brazil, but morphological and genetic analyses have shown that populations from Massachusetts to Caribbean actually refer to another species, validated as $A$. tractus [7].

In spite of the low diversity of Atlantic species when compared to Pacific and Indian oceans, surgeonfishes are a dominant fish group forming large assemblages in several reef areas from South Atlantic [3]. A. coeruleus specimens are usually solitary due to their territoriality behavior, while $A$. bahianus and A. chirurgus are commonly found in small to 


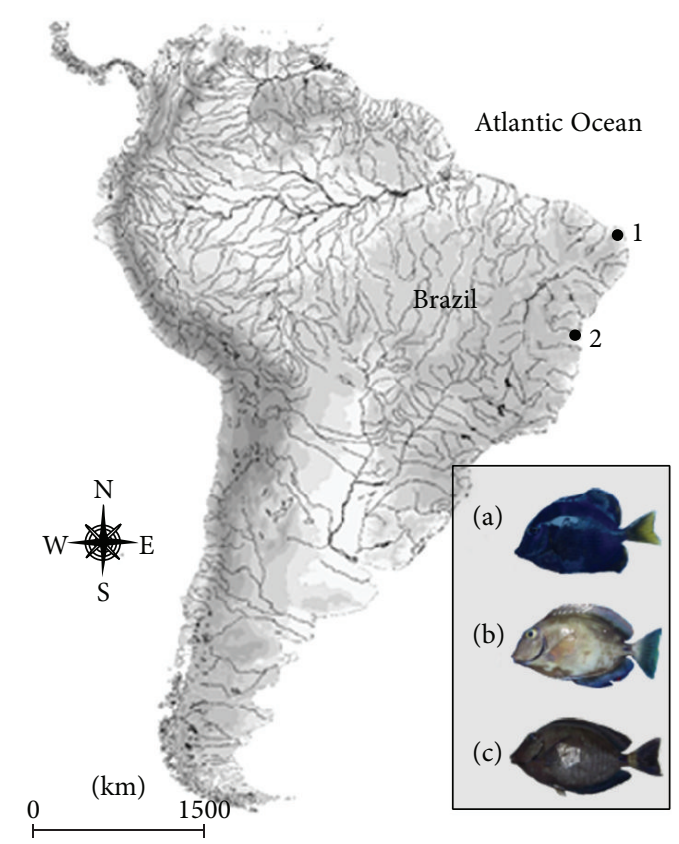

Figure 1: Map of South America showing the collections sites of Acanthurus coeruleus (a), A. bahianus (b), and A. chirurgus (c) in the states of Rio Grande do Norte (1) and Bahia (2), northeastern Brazil.

large schools, depending on the ontogenetic stage [10]. As most acanthurids, these species present relatively long pelagic larval stages with a mean duration from 51.6 to 55.2 days [11]. Usually, wide-range reef fish species with long pelagic larval development are characterized by a lack of genetic subdivision among populations [12] and low rates of chromosomal variation [13].

However, reports about cytogenetic patterns of Acanthuridae are still underrepresented (less than $5 \%$ of species) and restricted to Indo-Pacific species [14]. The three analyzed species from Pacific, Acanthurus triostegus, Prionurus scalprum [15], and Ctenochaetus striatus [16], all share a conservative Perciformes-like karyotype with $2 n=48$ a, considered basal to this fish group [17].

In order to increase the karyotypic data of Acanthuridae and to infer the chromosomal evolution of Atlantic species, cytogenetical analyses were carried out for three Acanthuridae species from Brazilian coast, South Atlantic.

\section{Material and Methods}

Nine individuals of Acanthurus coeruleus, four individuals of A. bahianus, and 17 individuals of $A$. chirurgus were cytogenetically studied. Animals were collected using hand nets (60 $\times 100 \mathrm{~cm}$ ) by snorkeling at coastal reef areas from the states of Rio Grande do Norte $\left(5^{\circ} 46^{\prime} \mathrm{S}, 35^{\circ} 12^{\prime} \mathrm{W}\right)$ and Bahia $\left(13^{\circ} 00^{\prime} \mathrm{S}\right.$, $38^{\circ} 32^{\prime} \mathrm{W}$ and $\left.13^{\circ} 52^{\prime} \mathrm{S}, 38^{\circ} 56^{\prime} \mathrm{W}\right)$ in northeastern Brazilian shore (Figure 1). Right after collection, specimens were transported in plastic bags with oxygen to the laboratories and placed in $60 \mathrm{~L}$ tanks equipped with filtration and aeration systems.
Twenty-four hours prior to chromosomal preparation, the animals were inoculated via intramuscular with a solution of antigen complexes (Munolan) for mitotic induction [18]. After this period, the specimens were anesthetized and euthanized by immersion in in water at $0-4^{\circ} \mathrm{C}$ up to complete interruption of gill movements [19]. To obtain mitotic chromosomes in vitro, portions of anterior kidney were removed and transferred to RPMI medium (Cultilab) with about $50 \mu \mathrm{L}$ of $0.025 \%$ colchicine, followed by hypotonic treatment (KCL $0.075 \mathrm{M}$ ) for 20 minutes at $37^{\circ} \mathrm{C}$ and fixation in Carnoy's fixative (methanol: acetic acid $3: 1$ ) [20]. Chromosomes were stained with $5 \%$ Giemsa in phosphate buffer $(\mathrm{pH}$ 6.8) for karyotypic analyses. Nucleolus organizer regions (NORs) were detected by silver nitrate staining (Ag-NORs) [21], whereas heterochromatic regions were evidenced by $\mathrm{C}$ banding [22].

Metaphases were photographed using an Olympus BX51 (Olympus, Tokyo, Japan) epifluorescence photomicroscope equipped with digital capture system. Chromosomes were classified as metacentric (m), submetacentric (sm), subtelocentric (st), and acrocentric (a) based on arm ratio [23]. The pairs were arranged in decreasing order size according to each morphological category ( $\mathrm{m}, \mathrm{sm}$, st, and a) in karyotypes using the software Adobe Photoshop CS6 v. 13.0.

\section{Results}

The three Acanthurus species showed remarkable karyotype diversification. Acanthurus coeruleus presented $2 n=$ 48 , composed of two submetacentric, four subtelocentric, and 42 acrocentric chromosomes (Figure 2(a)). The diploid 


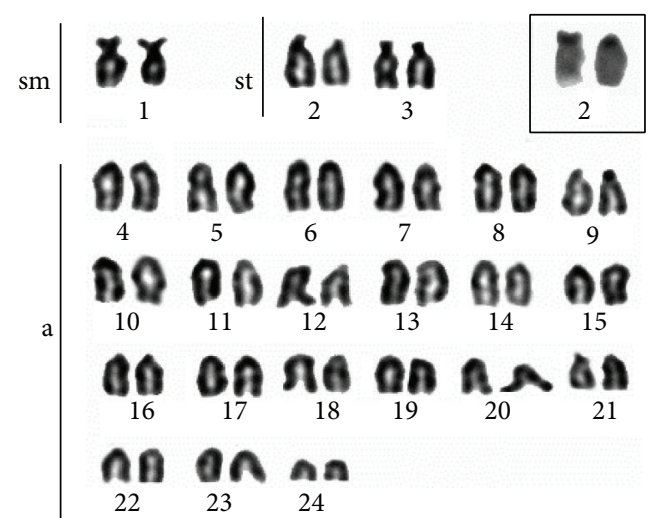

(a)

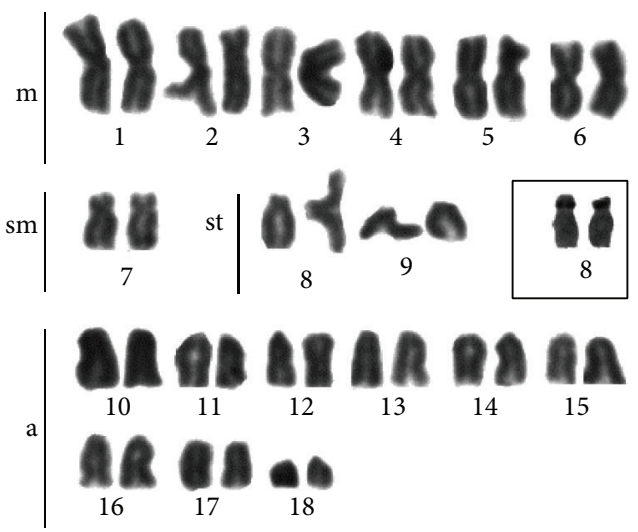

(c)
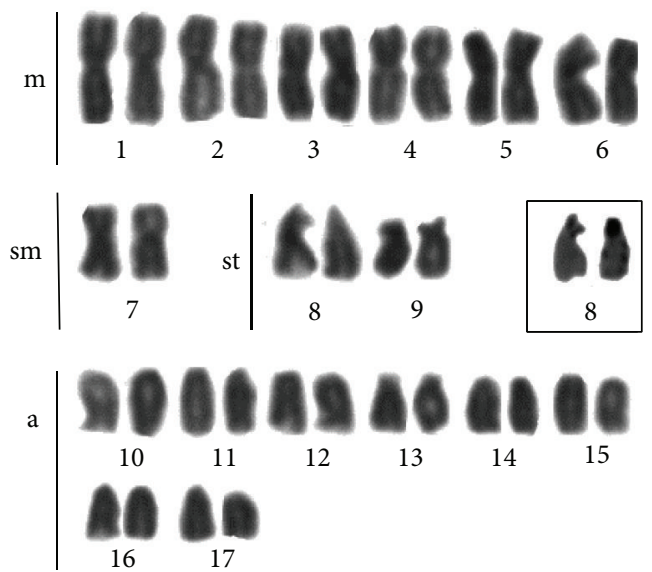

(e)
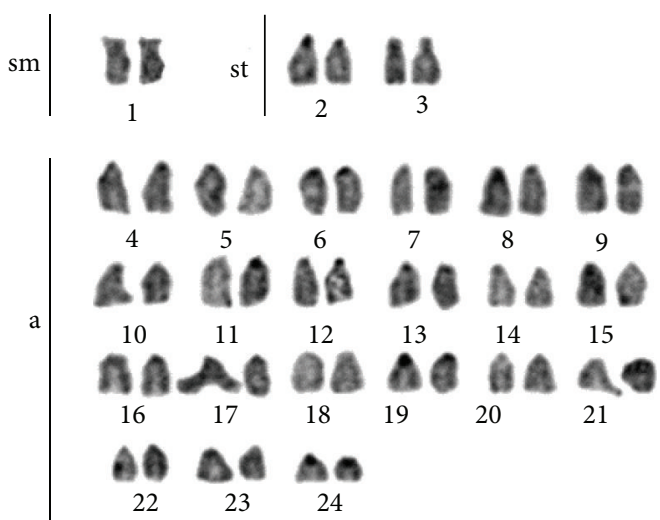

(b)

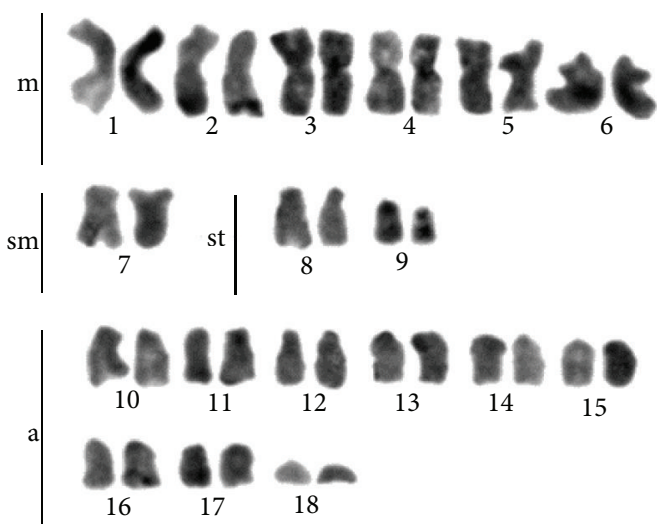

(d)
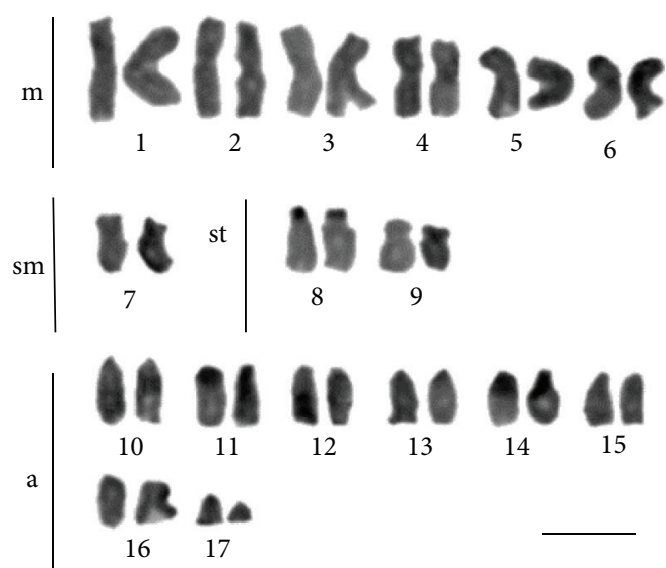

(f)

Figure 2: Karyotypes of Acanthurus coeruleus ((a) and (b)) with $2 n=48$, A. bahianus ((c) and (d)) with $2 n=36$, and A. chirurgus ((e) and (f)) with $2 n=34$ after conventional Giemsa staining ((a), (c), and (e)) and C-banding ((b), (d), and (f)). The NOR-bearing chromosomes after silver nitrate staining of each species are shown in boxes (pair 2 of A. coeruleus and pair 8 of A. bahianus and A. chirurgus).

number of $A$. bahianus equals $2 n=36$ with a karyotype composed of 12 large metacentric, two submetacentric, four subtelocentric, and 18 acrocentric chromosomes (Figure 2(c)) while $A$. chirurgus was characterized by 12 large metacentric, two submetacentric, four subtelocentric, and 16 acrocentric chromosomes $(2 n=34)$ (Figure 2(e)).

Small amounts of heterochromatin were detected mainly at pericentromeric regions and interspersed with NORs in studied species (Figures 2(b), 2(d), and 2(f)). In A. bahianus, terminal C-bands were also observed in some pairs (Figure 2(d)).

Single nucleolar organizer regions (NORs) were located by silver nitrate staining on short arms of the largest subtelocentric pair in the three Acanthuridae species (Figure 2, inbox).

Based on chromosomal data, idiograms were generated to highlight particular karyotype traits for each species and the inferred pathways of chromosomal differentiation based on 


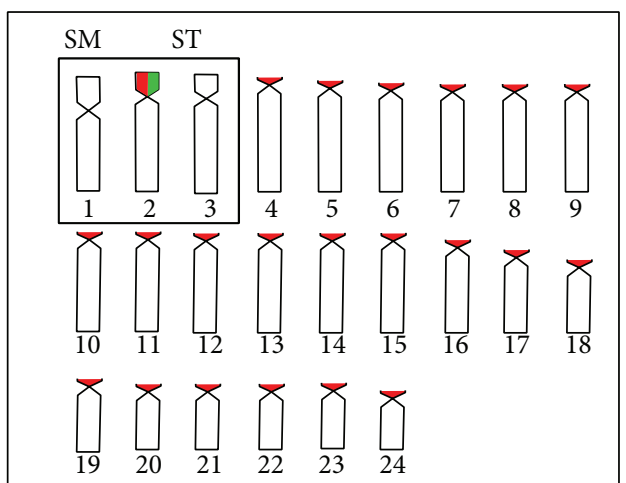

(a)

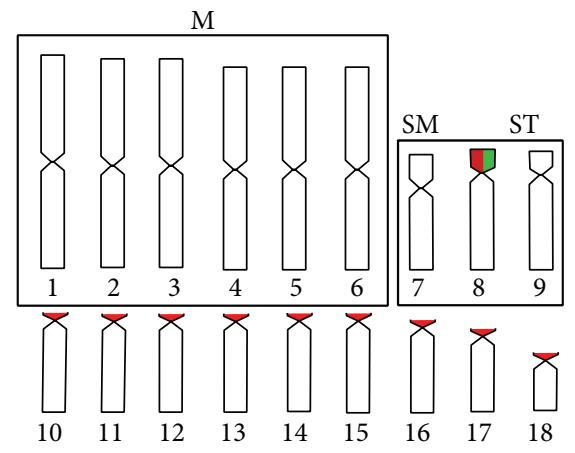

(b)

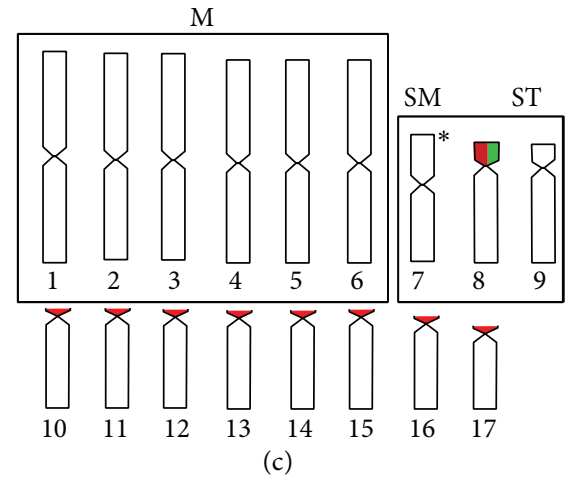

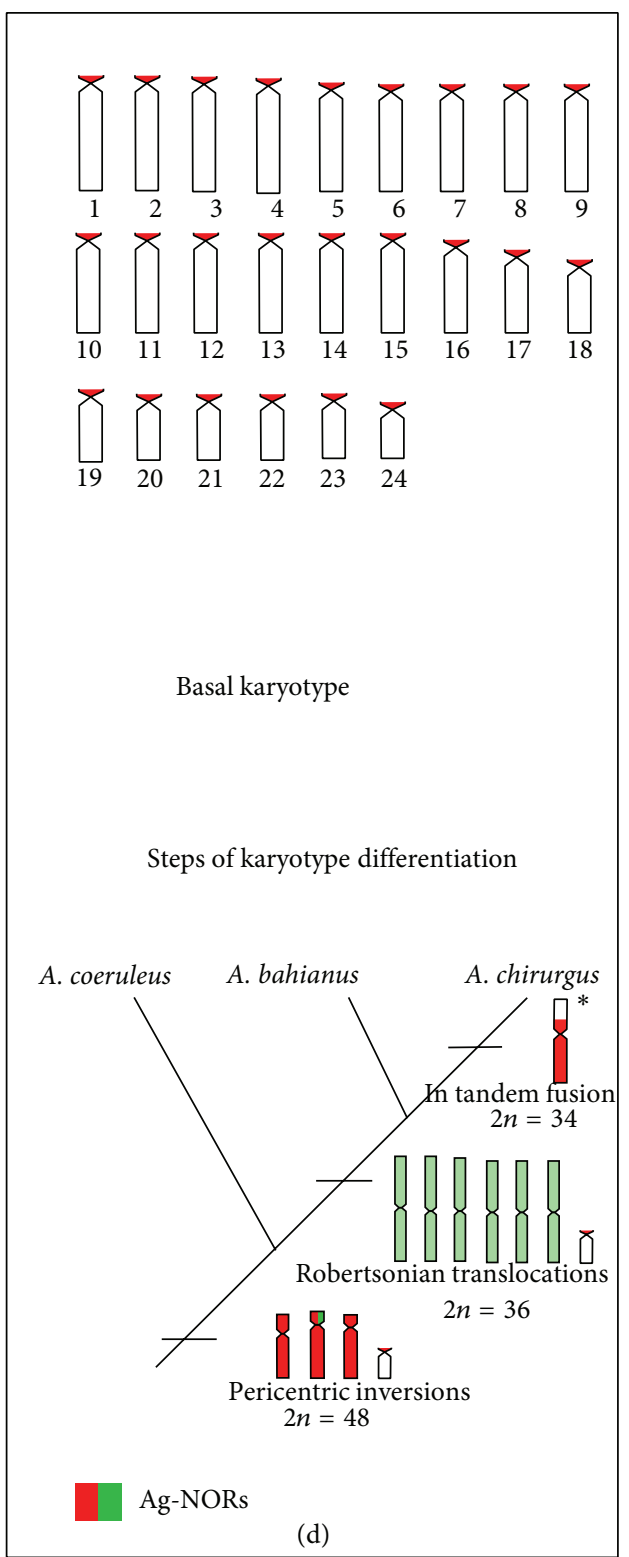

Figure 3: Idiograms of chromosomes sets of Acanthurus coeruleus (a), A. bahianus (b), and A. chirurgus (c) showing the most conspicuous shared cytogenetic traits in boxes. In $(\mathrm{d})$, the basal karyotype of Perciformes $(2 n=48 \mathrm{a})$ and a phylogenetic hypothesis based on sequential chromosomal rearrangements inferred in the three Acanthurus species.

a phylogenetic hypothesis to Atlantic Acanthurus (Figures $3(\mathrm{a})-3(\mathrm{~d}))$.

\section{Discussion}

It is assumed that the presence of 48 acrocentric chromosomes represents a plesiomorphic feature within Perciformes $[17,24]$. This condition is particularly frequent among marine fish and could be related to dispersal abilities (high gene flow) between populations, thereby preventing the fixation of new chromosomal rearrangements and karyotypic divergence [13]. In fact, the low genetic structure in reef fish species has been correlated to the production of planktonic eggs and/or larvae that can be dispersed over large distances [12].

This trend $(2 n=48 \mathrm{a})$ seems to be valid for Acanthuridae species from Indo-Pacific Ocean of different genera, such as Acanthurus, Ctenochaetus, and Prionurus [14]. However, inconsistent relationship between pelagic larval duration (PLD) and genetic connectivity or chromosomal patterns has been reported in some marine species [11, 25]. In these cases, ecological and biogeographic aspects of each species might be more relevant to explain the genetic variation than PLD itself, as observed in the present study.

As expected for widely distributed species with long PLD, A. coeruleus presented typical Perciformes-like features, that 
is, a diploid number of 48, single NORs, and a large number of acrocentric chromosomes (Figure 2(a)). The karyotype of this species $(2 \mathrm{sm}+4 \mathrm{st}+42 \mathrm{a})$ demonstrates the occurrence of pericentric inversions in three chromosome pairs (1st, 2nd, and 3rd pairs), a common rearrangement in Perciformes that accounts for most of karyotype diversification in marine fish [24]. A similar set of three chromosomal pairs in both morphology and size is also observed in A. bahianus and $A$. chirurgus, represented by a submetacentric pair and two subtelocentric pairs, including the NOR-bearing pair. Because of the high resemblance of such pairs in the three Acanthurus species, they are supposed to share a common origin before the differentiation of each lineage, thereby indicating a symplesiomorphic trait. Estimates of divergence time between the subclade that comprises $A$. coeruleus and that clusters $A$. chirurgus and A. tractus [2], a sister-species of A. bahianus, suggest that these putative homeologous pairs (sm and st) had arisen at nearly $19 \mathrm{Ma}$.

On the other hand, A. bahianus and A. chirurgus presented an evolutionary chromosomal pattern rarely found in typical marine fishes. The drastic reduction in diploid number from 48 chromosomes to $2 n=36$ and $2 n=34$, respectively, along the presence of large metacentric pairs is evidence of sequential Robertsonian rearrangements or centric fusions (Figures 2(c) and 2(e)). Indeed, the uniqueness of Robertsonian translocations in karyotypes of $A$. bahianus and A. chirurgus (Figure 3), and similar size of metacentric pairs reinforces these rearrangements are a recently shared trait between both species. An additional fusion representing an autapomorphic condition is presented in A. chirurgus karyotype since this species has an exclusive large sm pair (7th) and lacks the smallest acrocentric pair observed in the other two species (Figure 2(e)).

The chromosomal speciation observed in Acanthurus species of South Atlantic is likely to reflect historical events. Extensive analysis of biogeography and evolution of reef fish from Atlantic indicated that changes in ocean dynamics over the past $10 \mathrm{Ma}$ have determined the differential richness and endemism levels of fish genera and families of reef fish [26]. As discussed by Galetti et al. [24], the rate of chromosomal evolution in reef fish from Atlantic Ocean also seems to be strongly related to habitat isolation of coastal areas during glaciation periods followed by further sea level uprising.

Unfortunately, no reports about time of divergence between $A$. bahianus and $A$. chirurgus are available, thus hindering the minimum time span after Robertsonian rearrangements that gave rise to the large metacentric chromosomes, herein referred as a single trait. However, estimates inferred for $A$. chirurgus and $A$. tractus [2], being the latter a sibling species of $A$. bahianus [7], point out that these rearrangements took place by at least $5 \mathrm{Ma}$. Even though the time estimates for the occurrence of chromosomal fusions in both Acanthurus species might require some bias correction, they are intermediary to periods of major biogeographic isolation events in Atlantic Ocean such as Amazon outflow ( 10 Ma) and uplifting of Panama isthmus ( 3 Ma) [27]. Nonetheless, the influence of these biogeographic barriers in the putative fixation of chromosomal rearrangements remains unclear and further cytogenetic studies in other species, particularly A. tractus, are highly encouraged.
Different from pericentric inversions, centric fusions or Robertsonian rearrangements are usually reported in nonPerciformes marine fish, such as flatfish (Pleuronectiformes) [28], toadfish (Batrachoidiformes) [29], and some mullets (Mugiliformes) [30]. Centric fusions are particularly common in Batoidea (stingrays, guitarfish, and skates), the most derived superorder of elasmobranchs [31]. Conversely, these rearrangements have been scarcely identified in Perciformes at a polymorphic stage in Pomacentridae [32], Gobiidae [33, 34], Lutjanidae [35], Apogonidae [36, 37], and Uranoscopidae [38] or else restricted to a particular taxon like Sparisoma (parrotfishes) [39]. Therefore, the karyotypes of $A$. bahianus and $A$. chirurgus can be regarded as highly derived in relation to basal karyotype suggested to Perciformes.

While the macrostructure was variable, the NOR-bearing chromosomes seem to be conserved in the three species (Figure 2, inbox). This pattern indicates that these chromosomal regions as poor cytotaxonomic markers, differing from other Atlantic fishes in which the identification of ribosomal cistrons has proved to be efficient to distinguish apparently homogeneous karyotypes, as in Lutjanidae [40], Serranidae [41], and Gerreidae [42] or even population units [43, 44]. Similarly, heterochromatin was virtually similar among $A$. coeruleus, A. bahianus, and A. chirurgus, being mainly dispersed over centromeres and NORs, as commonly found in most Perciformes [45]. Therefore, it is unclear if the deep divergences in these fish karyotypes are followed by microstructural changes. Further analyses using other banding methodologies and mapping of sequences by fluorescence in situ hybridization (FISH) are required to evaluate the extension of such apparent homogeneity of specific chromosomal regions in Acanthurus.

The amount of chromosomal traits in the three Acanthurus species from Brazilian coast allows raising a phylogenetic hypothesis to them. Indeed, the ordination and sharing of the traits show a closer phylogenetic relationship between $A$. bahianus and $A$. chirurgus than to $A$. coeruleus. This result is corroborated by previous genetic analyses. Indeed, analysis of $C y t B$ sequences showed a more basal condition between $A$. coeruleus in relation to the other two congeners [7]. Recently, a phylogenetic analysis of Acanthuridae based on sequence data of two mitochondrial and seven nuclear genes [2] corroborated the ancestral position of $A$. coeruleus in relation to $A$. chirurgus and $A$. tractus, which replaces $A$. bahianus in the Caribbean $[7,46]$.

Thus, for analyzed Atlantic species, the chromosomal traits show robust support to clarify the phylogenetic arrangement among them serving as useful markers to evolutionary studies in Acanthuridae. Moreover, in agreement with phylogeographic studies [11, 26], the chromosomal differences between Atlantic species of Acanthurus seem to be more related to ecology and evolutionary history than to dispersal potential since the three species share a relatively long PLD.

\section{Conclusion}

In conclusion, the chromosomal analyses in Acanthurus allowed identifying sequential events related to speciation 
process that differ from most cytogenetical reports on marine Perciformes, where specific rearrangements are often unclear. A step-by-step karyotype modification can be inferred from the most basal pattern, involving few structural rearrangements (pericentric inversions in A. coeruleus) to high derived ones, originated by Robertsonian fusions in both $A$. bahianus and $A$. chirurgus and additional in tandem fusion in $A$. chirur$g u s$. This scenario reveals a unique condition to tracing back the order of chromosomal evolutionary changes in Atlantic surgeonfish.

\section{Conflict of Interests}

The authors declare that there is no conflict of interests regarding the publication of this paper.

\section{Acknowledgments}

The authors thank CAPES, CNPq (no. 556793/2009-9), INCT "Ciências do Mar," and FAPESB (no. APP0064/2011) for the financial support and ICMBio/SISBIO (licenses 19135-1, 131360-1, and 27027-2) for the authorization in collecting specimens. They are also grateful to Dr. José Garcia Júnior for the taxonomic identification of specimens.

\section{References}

[1] J. S. Nelson, Fishes of the World, John Wiley \& Sons, New York, NY, USA, 3rd edition, 2006.

[2] L. Sorenson, F. Santini, G. Carnevale, and M. E. Alfaro, "A multilocus timetree of surgeonfishes (Acanthuridae, Percomorpha), with revised family taxonomy," Molecular Phylogenetics and Evolution, vol. 68, no. 1, pp. 150-160, 2013.

[3] K. L. Tang, P. B. Berendzen, E. O. Wiley, J. F. Morrissey, R. Winterbottom, and G. D. Johnson, "The phylogenetic relationships of the suborder Acanthuroidei (Teleostei: Perciformes) based on molecular and morphological evidence," Molecular Phylogenetics and Evolution, vol. 11, no. 3, pp. 415-425, 1999.

[4] R. C. Guiasu and R. Winterbottom, "Osteological evidence for the phylogeny of recent genera of surgeonfishes (Percomorpha, Acanthuridae)," Copeia, no. 2, pp. 300-312, 1993.

[5] K. D. Clements, R. D. Gray, and J. H. Choat, "Rapid evolutionary divergences in reef fishes of the family Acanthuridae (Perciformes: Teleostei)," Molecular Phylogenetics and Evolution, vol. 26, no. 2, pp. 190-201, 2003.

[6] R. B. Francini-Filho, C. M. Ferreira, E. O. C. Coni, R. L. De Moura, and L. Kaufman, "Foraging activity of roving herbivorous reef fish (Acanthuridae and Scaridae) in eastern Brazil: Influence of resource availability and interference competition," Journal of the Marine Biological Association of the United Kingdom, vol. 90, no. 3, pp. 481-492, 2010.

[7] M. A. Bernal and L. A. Rocha, "Acanthurus tractus Poey, 1860, a valid western atlantic species of surgeonfish (Teleostei, Acanthuridae), distinct from Acanthurus bahianus Castelnau, 1855," Zootaxa, vol. 2905, pp. 63-68, 2011.

[8] J. L. Figueiredo and N. A. Menezes, Manual de Peixes Marinhos do Sudeste do Brasil. VI. Teleostei (5), Museu de Zoologia, Universidade de São Paulo, São Paulo, Brazil, 2000.

[9] O. J. Luiz Jr., S. R. Floeter, J. L. Gasparini, C. E. L. Ferreira, and P. Wirtz, "The occurrence of Acanthurus monroviae (Perciformes:
Acanthuridae) in the south-western Atlantic, with comments on other eastern Atlantic reef fishes occurring in Brazil," Journal of Fish Biology, vol. 65, no. 4, pp. 1173-1179, 2004.

[10] G. L. Lawson, D. L. Kramer, and W. Hunte, "Size-related habitat use and schooling behavior in two species of surgeonfish (Acanthurus bahianus and A. coeruleus) on a fringing reef in Barbados, West Indies," Environmental Biology of Fishes, vol. 54, no. 1, pp. 19-33, 1999.

[11] L. A. Rocha, A. L. Bass, D. R. Robertson, and B. W. Bowen, "Adult habitat preferences, larval dispersal, and the comparative phylogeography of three Atlantic surgeonfishes (Teleostei: Acanthuridae)," Molecular Ecology, vol. 11, no. 2, pp. 243-252, 2002.

[12] J. A. Eble, L. A. Rocha, M. T. Craig, and B. W. Bowen, "Not all larvae stay close to home: insights into marine population connectivity with a focus on the brown surgeonfish (Acanthurus nigrofuscus)," Journal of Marine Biology, vol. 2011, Article ID 518516, 12 pages, 2011.

[13] W. F. Molina, "Chromosomal changes and stasis in marine fish groups," in Fish Cytogenetics, E. Pisano, C. Ozouf-Costaz, F. Foresti, and B. G. Kapoor, Eds., pp. 69-110, Science Publishers, Enfield, NH, USA, 2007.

[14] R. Arai, Fish Karyotypes. A Check List, Springer, Tokyo, Japan, 2011.

[15] R. Arai and M. Inoue, "Chromosomes of seven species of Pomacentridae and two species of Acanthuridae from Japan," Bulletin of the National Science Museum A, vol. 2, pp. 73-78, 1976.

[16] Y. Ojima and K. Yamamoto, "Cellular DNA contents of fishes determined by flow cytometry," Kromosomo, vol. 57, pp. 1871$1888,1990$.

[17] M. J. I. Brum and P. M. Galetti Jr., "Teleostei ground plan karyotype," Journal of Comparative Biology, vol. 2, pp. 91-102, 1997.

[18] W. F. Molina, D. E. Alves, W. C. Araújo, P. A. Martinez, M. F. Silva, and G. W. Costa, "Performance of human immunostimulating agents in the improvement of fish cytogenetic preparations," Genetics and Molecular Research, vol. 9, no. 3, pp. 1807$1814,2010$.

[19] J. J. Blessing, J. C. Marshall, and S. R. Balcombe, "Humane killing of fishes for scientific research: a comparison of two methods," Journal of Fish Biology, vol. 76, no. 10, pp. 2571-2577, 2010.

[20] J. R. Gold, C. Lee, N. S. Shipley, and P. K. Powers, "Improved methods for working with fish chromosomes with a review of metaphase chromosome banding," Journal of Fish Biology, vol. 37, no. 4, pp. 563-575, 1990.

[21] W. M. Howell and D. A. Black, "Controlled silver-staining of nucleolus organizer regions with a protective colloidal developer: a 1-step method," Experientia, vol. 36, no. 8, pp. 1014-1015, 1980.

[22] A. T. Sumner, "A simple technique for demonstrating centromeric heterochromatin," Experimental Cell Research, vol. 75, no. 1, pp. 304-306, 1972.

[23] A. Levan, K. Fredga, and A. A. Sandberg, "Nomenclature for centromeric position on chromosomes," Hereditas, vol. 52, pp. 201-220, 1964.

[24] P. M. Galetti Jr., W. F. Molina, P. R. A. M. Affonso, and C. T. Aguilar, "Assessing genetic diversity of Brazilian reef fishes by chromosomal and DNA markers," Genetica, vol. 126, no. 1-2, pp. 161-177, 2006. 
[25] P. R. A. De Mello Affonso and P. M. Galetti Jr., "Chromosomal diversification of reef fishes from genus Centropyge (Perciformes, Pomacanthidae)," Genetica, vol. 123, no. 3, pp. 227-233, 2005.

[26] S. R. Floeter, L. A. Rocha, D. R. Robertson et al., "Atlantic reef fish biogeography and evolution," Journal of Biogeography, vol. 35, no. 1, pp. 22-47, 2008.

[27] L. A. Rocha, "Patterns of distribution and processes of speciation in Brazilian reef fishes," Journal of Biogeography, vol. 30, no. 8, pp. 1161-1171, 2003.

[28] J. A. Bitencourt, I. Sampaio, R. T. C. Ramos, and P. R. A. M. Affonso, "Chromosomal fusion in Brazilian populations of Trinectes inscriptus Gosse, 1851 (Pleuronectiformes; Achiridae) as revealed by internal telomere sequences (ITS)," Journal of Experimental Marine Biology and Ecology, vol. 452, pp. 101-104, 2014.

[29] G. W. W. F. Costa and W. F. Molina, "Karyoevolution of the toadfish Thalassophryne nattereri (Batrachoidiformes: Batrachoididae)," Genetics and Molecular Research, vol. 8, no. 3, pp. 1099-1106, 2009.

[30] M. Nirchio, R. Cipriano, M. Cestari, and A. Fenocchio, "Cytogenetical and morphological features reveal significant differences among Venezuelan and Brazilian samples of Mugil curema (Teleostei: Mugilidae)," Neotropical Ichthyology, vol. 3, no. 1, pp. 107-110, 2005.

[31] L. Rocco, I. Liguori, D. Costagliola, M. A. Morescalchi, F. Tinti, and V. Stingo, "Molecular and karyological aspects of Batoidea (Chondrichthyes, Elasmobranchi) phylogeny," Gene, vol. 389, no. 1, pp. 80-86, 2007.

[32] W. F. Molina and P. M. Galetti Jr., "Robertsonian rearrangements in the reef fish Chromis (Perciformes, Pomacentridae) involving chromosomes bearing 5s rRNA genes," Genetics and Molecular Biology, vol. 25, no. 4, pp. 373-377, 2002.

[33] V. Giles, G. Thode, and M. C. Alvarez, "A new Robertsonian fusion in the multiple chromosome polymorphism of a Mediterranean population of Gobius paganellus (Gobiidae, Perciformes)," Heredity, vol. 55, pp. 255-260, 1985.

[34] G. Thode, V. Giles, and M. C. Alvarez, "Multiple chromosome polymorphism in Gobius paganellus (Teleostei, Perciformes)," Heredity, vol. 54, no. 1, pp. 3-7, 1985.

[35] M. Nirchio, R. Rondón, C. Oliveira et al., "Cytogenetic studies in three species of Lutjanus (Perciformes: Lutjanidae: Lutjaninae) from the Isla Margarita, Venezuela," Neotropical Ichthyology, vol. 6, no. 1, pp. 101-108, 2008.

[36] Y. Ojima and K. Kojima, "Chromosomal polymorphisms in Apogonidae fishes," Proceedings of the Japan Academy B, vol. 61, pp. 79-82, 1985.

[37] K. A. Rivlin, J. W. Rachlin, and G. Dale, "Intraspecific chromosomal variation in Apogon binotatus (Perciformes: Apogonidae) from the Florida Keys and St. Croix," Annals of the New York Academy of Sciences, vol. 494, pp. 263-265, 1987.

[38] R. Vitturi, E. Catalano, M. R. Lo Conte, A. M. Alessi, F. P. Amico, and D. Colombera, "Intra-populational and intra-individual mosaicisms of Uranoscoper scaber L. (Perciformes, Uranoscopidae)," Heredity, vol. 67, pp. 325-330, 1991.

[39] D. C. S. Sena and W. F. Molina, "Robertsonian rearrangements and pericentric inversions in Scaridae fish (Perciformes)," Genetics and Molecular Research, vol. 6, no. 3, pp. 575-580, 2007.

[40] É. C. Rocha and W. F. Molina, "Cytogenetic analysis in western Atlantic snappers (Perciformes, Lutjanidae)," Genetics and Molecular Biology, vol. 31, no. 2, pp. 461-467, 2008.
[41] W. F. Molina, F. A. Maia-Lima, and P. R. A. M. Affonso, "Divergence between karyotypical pattern and speciation events in Serranidae fish (Perciformes)," Caryologia, vol. 55, no. 4, pp. 299-305, 2002.

[42] L. L. Calado, L. A. C. Bertollo, G. W. W. F. D. Costa, and W. F. Molina, "Cytogenetic studies of Atlantic mojarras (Perciformes: Gerreidae): chromosomal mapping of $5 \mathrm{~S}$ and $18 \mathrm{~S}$ ribosomal genes using double FISH," Aquaculture Research, vol. 44, no. 5, pp. 829-835, 2012.

[43] D. C. S. de Sena and W. F. Molina, "Chromosomal rearrangements associated with pelagic larval duration in Labridae (Perciformes)," Journal of Experimental Marine Biology and Ecology, vol. 353, no. 2, pp. 203-210, 2007.

[44] I. V. Accioly, L. A. C. Bertollo, G. W. W. F. Costa, U. P. Jacobina, and W. F. Molina, "Chromosomal population structuring in carangids (Perciformes) between the north-eastern and southeastern coasts of Brazil," African Journal of Marine Science, vol. 34, no. 3, pp. 383-389, 2012.

[45] W. F. Molina, G. W. W. F. Costa, R. X. Soares et al., "Extensive chromosome conservatism in Atlantic butterflyfishes, genus Chaetodon Linnaeus, 1758: implications for the high hybridization success," Zoologischer Anzeiger, vol. 253, pp. 137-142, 2013.

[46] J. Castellanos-Gell, A. Robainas-Barcia, D. Casane, P. ChevalierMonteagudo, F. Pina-Amargós, and E. García-Machado, "The surgeonfish, Acanthurus bahianus, has crossed the AmazonOrinoco outflow barrier," Marine Biology, vol. 159, no. 7, pp. 1561-1565, 2012. 

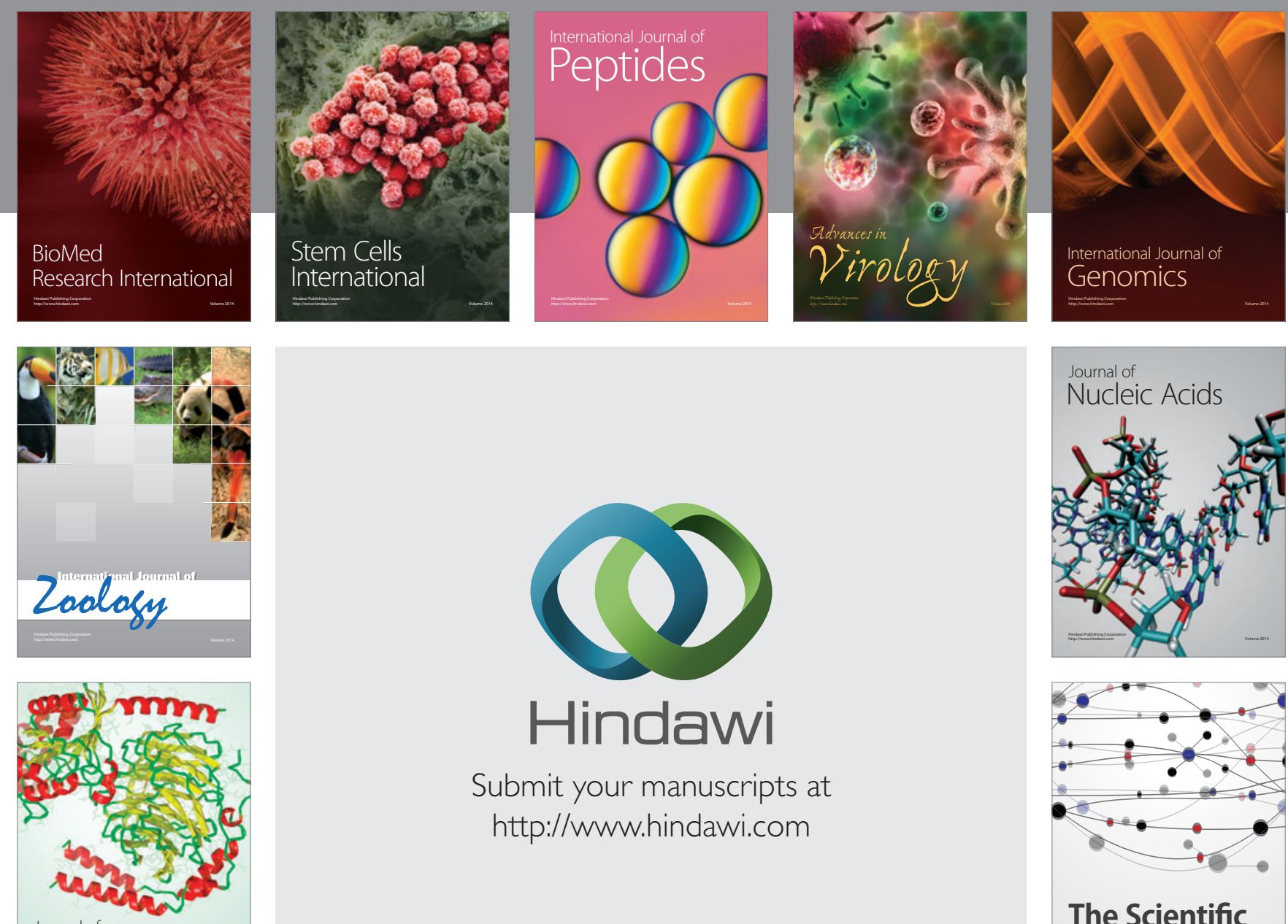

Submit your manuscripts at

http://www.hindawi.com

Journal of
Signal Transduction
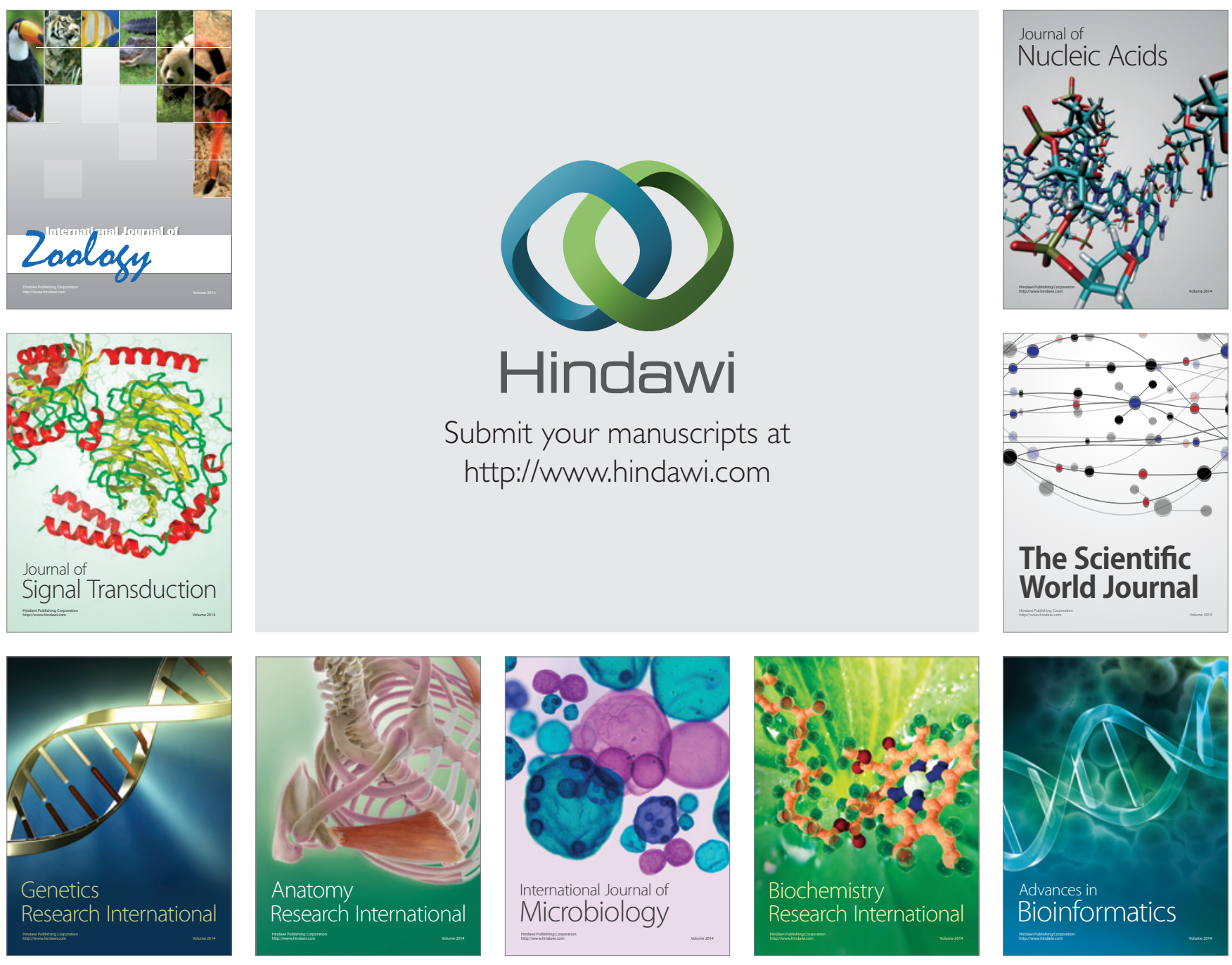

The Scientific World Journal
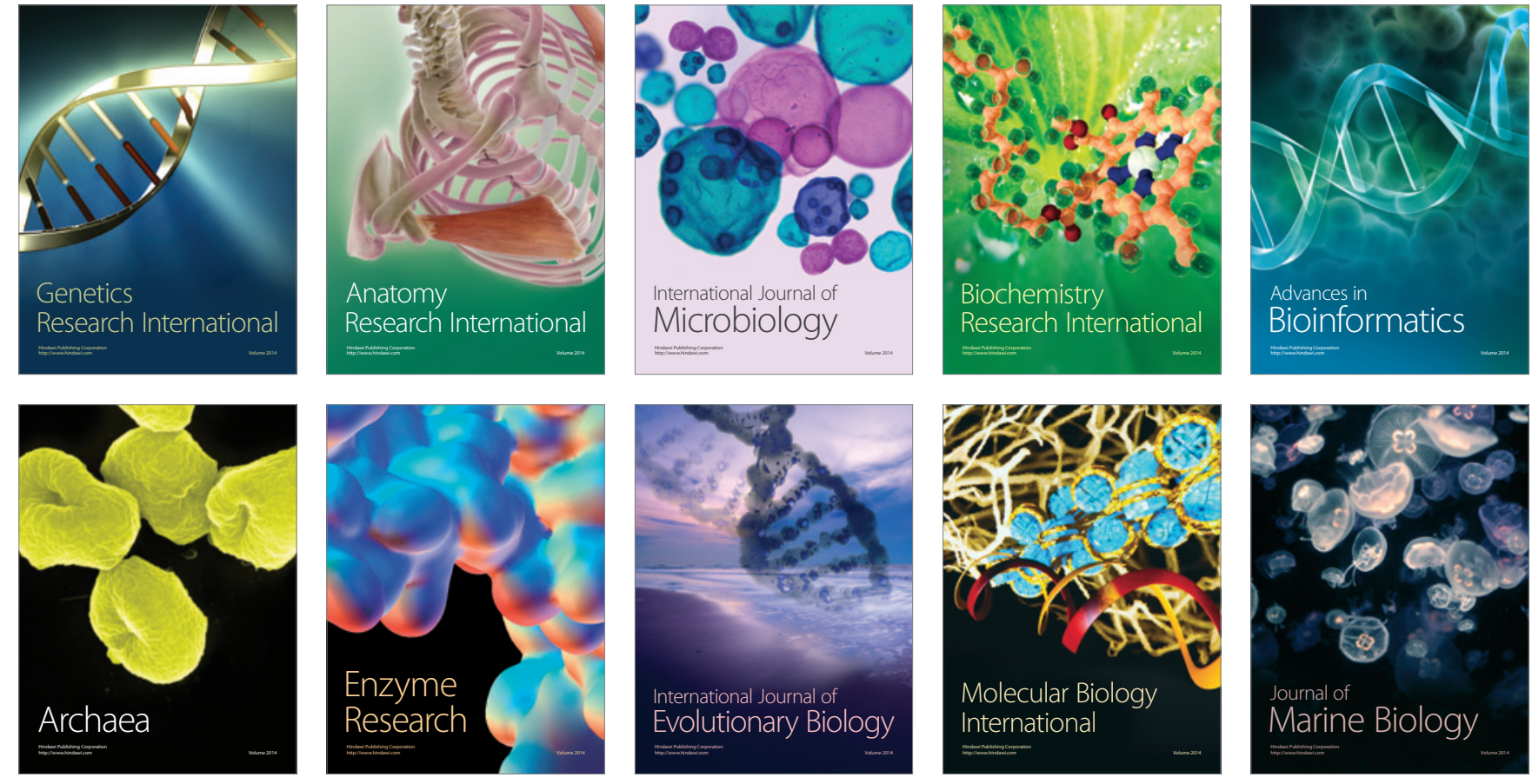